\title{
Chapter 9 \\ Outsourcing Risk Governance: Using \\ Consultants to Deliver Regulatory \\ Functions
}

\author{
Jan Hayes, Lynne Chester, and Dolruedee Kramnaimuang King
}

\begin{abstract}
The Australian gas supply industry provides a case study of outsourcing by economic regulators. These regulatory agencies rely on the engagement of external consultants for technical expertise who are effectively tasked with finding ways to reduce proposed expenditure, even for safety-related items. Empirical evidence shows that economic regulators uncritically accept this advice. Such outsourcing raises the possibility of significant impact on technical regulatory outcomes.
\end{abstract}

Keywords Economic regulation $\cdot$ Gas industry $\cdot$ Expert consultants $\cdot$ Public safety $\cdot$ Risk management

\subsection{Introduction}

Since the early 1990s, there have been significant changes to the governance of utilities such as electricity and gas, communications and transport which were owned and operated by government. These previously vertically integrated monopolies have undergone restructuring with segments being privatised and subjected to competition. Where such segments have natural monopoly characteristics, they continue to be subject to government control in the form of economic regulation. Each sector is also subject to technical regulation to ensure that safety and quality standards are maintained. Both kinds of regulation have been influenced by another significant public policy change. Deregulation, or 'red tape reduction', has meant effectively a move from prescription towards goal-based regulation combined with forms of

\footnotetext{
J. Hayes ( $\varangle)$

RMIT University, Melbourne, Australia

e-mail: jan.hayes2@rmit.edu.au

L. Chester

The University of Sydney, Sydney, Australia

D. K. King

Massey University, Palmerston North, New Zealand 
self-regulation governance. This has occurred across a range of sectors, including the technical and economic regulation of utilities.

Concurrently, an increased reliance on competitive market forces has resulted in a progressive rise in outsourcing and contracting-out across the private sector. This chapter considers one form of outsourcing adopted in the regulatory environment, that is, the use of contractors to perform assessments and evaluations to assist an economic regulator to perform its functions. We believe the use of contractors and consultants by regulatory agencies is not uncommon; yet it has received little academic attention despite the potentially significant implications. We address this issue by drawing on our empirical research regarding the impact on technical compliance, and thus safety, of the economic regulatory regime for the Australian gas pipeline and distribution network (gas supply) sector.

\subsection{Effective Regulation and Effective Regulators}

Proponents of a market-based approach to regulation emphasise that, in addition to state regulation, industries 'self-regulate' using industry standards, norms established by industry associations and similar. Ayres and Braithwaite [1] support the need for responsive regulation, i.e. to use a mixture of state regulation and self-regulation, and a range of strategies from encouragement to sanctions to ensure compliance. Policy regarding responsive regulation has been influential although it 'has been joined ... by "risk-based" regulation' [2, p. 65]. In risk-based or goal-setting regulation, the regulations require that companies use a risk-based process to ensure that outcomes are adequately addressed, rather than prescribing detailed measures that companies must take.

The change in regulatory policy and frameworks has led to change in the dayto-day practices of regulatory agencies. Regulators are now required to assess such questions as 'how well the duty holder has carried out the risk management process and how effective its controls are' [8, p. 210]. They may also seek to influence duty holders to comply by interacting with a broad range of stakeholders including company executives, extending well beyond the skills of many traditional inspectors [4].

The subject of our empirical research, the Australian gas supply sector, is subject to goal-based technical regulation that seeks to ensure public risk - as a result of pipeline failure-is reduced to a level that is as low as reasonably practicable. Questions of regulator capacity are key to the integrity of outcomes.

\subsection{Outsourcing of Regulatory Functions}

The privatisation and deregulation agenda has seen many formerly government operations move to the private sector. Most commonly, these have been service delivery 
operations. Of interest here are a different set of government operations linked to regulatory oversight. In such cases, public good outcomes do not necessarily align with the commercial imperatives driving private sector providers.

The building construction sector in the UK provides one example of the possible link between privatised-outsourced-regulatory functions and public safety outcomes. Regulations address a range of requirements for the quality of building works. A key regulatory function is building inspection to check that work has been done to the requisite standard before permits are issued. Part privatisation of this function has raised concerns about the extent to which the actions of inspectors are driven by commercial pressure from clients, rather than a desire to enforce compliance with relevant standards [6].

The UK is not alone in this style of building control regulatory enforcement. Changes to privatise building control came about through a combination of both top down and bottom up pressures. Introducing private sector inspectors in several countries, including Australia, has been driven by government policy in the search for greater efficiency and effectiveness. One study of private sector involvement in building control in three Australian states found that it had 'resulted in more technical efficiency and effectiveness of regulatory enforcement' [9, p. 206]. Private sector involvement was seen to increase the skill level of inspectors overall. On the other hand, there are also negative effects. Private sector involvement is seen to have an adverse impact on accountability as conflicts of interest and weak auditing can result in lack of effective oversight. Similar results were found in building inspection practices in several Canadian states [10].

\subsection{Economic and Technical Regulation of Gas Supply}

Our case study focuses on the interaction of economic and safety/technical regulation. Utilities such as the supply of natural gas are considered natural monopolies. Economic theory assumes that the prices charged by a monopolist will be set at a level that generates excessive profit, and thus, there is a need for economic (price) regulation in the absence of the pressures of market competition.

Textbook theories of optimal pricing for regulated businesses assume that regulators are fully informed about costs, technology, and consumer demand and can therefore impose cost minimisation obligations on the regulated business. In reality, regulators have imperfect and less information than the regulated business. Consequently, issues of relevant experience and expertise on the part of economic regulators are critical as we will show.

A key consideration for economic regulation is the need to balance the interests of investors wishing to make an adequate return, with the interests of consumers who many be subject to exploitation in monopoly conditions [3]. This objective acts in tension with technical regulation to encourage expenditure on items such as maintenance and inspection to ensure public safety is maintained. In summary, the interaction between company and regulatory practices operates as follows: 
1. A need for physical system changes is identified by a regulated business in accordance with the risk management processes of technical legislation and standards.

2. The business submits a safety case update to the technical regulator who assesses it inhouse and ultimately grants approval.

3. The regulated business then submits a proposal to the economic regulator which contains risk-based arguments for expenditure to comply with its approved safety case.

4. The economic regulator assesses the proposed safety expenditure using external consultant advice which interprets and applies technical regulatory requirements that commonly differ from that of the regulated business.

5. The economic regulator does not consider a regulated business' compliance with a safety case to be tantamount to a regulatory obligation of the economic regulatory regime.

6. The economic regulator determines, based on the advice of its external consultants, that a regulated business can spend less than it has proposed for safety purposes.

7. The regulated business, in light of the economic regulator's decision for approved expenditure, reviews its asset management strategies which may include revision of asset risk profiles.

8. Should a regulated business decide to spend more than that approved by the economic regulator for safety expenditure, there is no guarantee that this additional expenditure will be approved by the economic regulator.

These steps demonstrate the convoluted decision-making process regarding safety expenditure that the dual regulatory regimes impose on regulated businesses.

\subsection{Method}

Our empirical study collected qualitative information through semi-structured interviews, and conducted a document analysis, to gain an understanding of the economic and technical regulatory frameworks and how they operate in practice.

Forty-nine semi-structured interviews were conducted with senior employees of: the Australian Economic Regulator (AER); the Economic Regulation Authority of Western Australia (WAERA); the technical regulators from four Australian states (New South Wales, Victoria, South Australia and Western Australia); eight companies with majority ownership interests in six Australian gas transmission pipeline and eight distribution networks (in all Australian states and territories except Tasmania) subject to full economic regulation; peak industry bodies; and, current or former consultants to the gas sector.

The document analysis included the determinations of economic regulators, proposals submitted by companies to economic regulators, the performance reporting of technical regulators, and annual company reports (including financial statements). 
We also examined in-depth five case studies from AER and WAERA decisions that directly related to proposed company expenditure for safety and asset integrity purposes.

\subsection{Findings}

Our analysis found that the technical and economic regulatory regimes are in significant tension [7]. The amount and timing of expenditure on projects linked to pipeline integrity is impacted by the decisions of the economic regulator. This is not to suggest that, despite decisions by the economic regulator, we found any regulated gas business would fail to spend money on something that they considered to be an immediate safety problem. The impact is far more subtle.

The safety of gas supply systems is 'a dynamic non-event'. For low frequency events such as major pipeline failures, the past is not a good predictor of future performance. It is easy to become complacent given that the warning signs of failure can be hard to spot. In this operating environment, significant investment in both time and money is required to ensure that the state of the system, including all risk controls, is well understood, and small problems are identified and monitored or fixed to prevent a catastrophe in the future. The technical regulatory regime is designed with this in mind but the economic regulatory regime takes a very different orientation towards all expenditure, even that which is safety-related.

One key factor uncovered by our research is the use of technical consultants by the economic regulator and the influence that consultant advice has on determinations. Many gas company participants expressed criticisms and frustrations about the consultants engaged by the economic regulator. Limited availability of expertise, poor choices, questionable independent advice, and conflicts of interest were consistent themes in the comments of company participants.

On the subject of expertise, company participants were particularly critical of the lack of specialist knowledge in the consultants engaged by the economic regulator, emphasising that consultants often had no relevant gas industry experience at all.

If the issue was simply lack of expertise, we might expect a variation in the assessment of company expenditure proposals with consultants suggesting either more or less expenditure is warranted. In fact, we found the proposed variation is always in one direction. The economic regulator's consultants are always of the view that the proposed expenditure is too high. According to some company interviewees, this reflects the implicit scope of consultants' work set by the economic regulator. In their view, the consultants are effectively paid to make the argument that the cost information provided by companies is inflated.

The consultants' task includes the provision of significant expert judgement, and company interviewees were of the view that consultants have a conflict of interest. 
There are financial and reputational benefits in working for the economic regulator. As a result, consultant advice tends to support the economic regulator's position that companies overestimate necessary expenditure and so consultants typically 'conclude' that proposed expenditure is more than required to ensure system safety.

Gas supply companies also use external expertise, and this limits the consultant pool for the economic regulator due to conflicts of interest in that consultants cannot take on work reviewing regulatory submissions written by companies that are their clients. Both gas companies and regulators agree that this creates difficulties, effectively excluding many experts from working with the economic regulators due to conflict of interest issues.

Our study also included an in-depth review of five case studies of economic regulatory determinations which show the very influential role that external consultants play in forming the economic regulator's understanding of safety and its subsequent decisions. In all cases, the economic regulator accepted the expert consultant's assessment and recommendations.

In one case study, the regulated business proposed expenditure for modifications to the pipeline system to allow comprehensive integrity testing. The AER's consultant concluded such testing was not required and negotiation between the economic regulator and the regulated business moved to known failure mechanisms versus unknown failure mechanisms that inspection is designed to find. This demonstrates poor risk management practices on the part of the economic regulator's consultant and a very different orientation towards risk than that adopted by the regulated business. The expenditure proposed by the regulated business was largely disallowed.

Two other similar case studies illustrated very different interpretations between a consultant's understanding-accepted by the economic regulator-and a gas supply company's understanding of the requirements of the risk assessment frameworks of the relevant industry standards.

The case study of mains replacement programs for three gas distribution networks demonstrated that the economic regulator's decision to approve less capex than proposed by the businesses rested upon an interpretation of mandatory safety expenditure. The economic regulator concluded — based on its consultant's advice - that the volume of mains replacement specified in a safety case is indicative rather than mandatory (in fact, discretionary), and there are alternatives to mains replacement. This means the economic regulator considers that because there are options to manage mains risk, and the past volume replacement rates were well below forecasts, a company has discretion to manage mains risk.

Why does an economic regulator use external consultants? The answer lies in resourcing. Company interviewees were consistently critical-and often quite strongly — of the capacity and expertise of the economic regulator. Inexperienced staff, understaffing, high staff turnover, and poor operational and business understanding of analysts were constant themes in company interviewee comments who considered that these factors negatively impacted company processes and outcomes.

In summary, the economic regulator makes extensive use of external technical expertise because there are no equivalent internal resources. The availability of these specialised consultants is limited and many work for the gas supply companies which 
precludes them from providing expert advice to economic regulators due to the potential conflict of interest. For those consultants engaged by economic regulators, a different conflict of interest arises. These consultants are acutely aware of the economic regulator's position that a company's proposed expenditure should be reduced and produce advice to that effect. This situation is confirmed by our interview data and in-depth case studies of approved expenditure for regulated gas supply systems.

\subsection{Discussion}

Modern corporate regulation includes self-regulatory mechanisms that draw on private sector expertise. Peer pressure can provide an enforcement mechanism that may encourage and persuade industry actors to meet established norms and ensure that some companies that would otherwise have lower standards operate closer to what is typical $[1,2]$. Despite this possibility, we see that use of consultants by economic regulators is not providing such a mechanism.

The two state-based regulatory mechanisms - economic and technical—are in conflict given their different objectives-lowest consumer price in one case and acceptable risk to the public in the other. This is problematic in its own right. What we have seen, however, is that use of consultants is exacerbating this division. As technical experts, consultants have the potential to contribute to resolution of the appropriate balance between these multiple objectives but they do not act in this way. Rather, we see them adopting one side of the conflict- that of the economic regulator-which aligns with their own financial interests. Such market-driven behaviour is to be expected, but it is not in the interests of the best regulatory outcomes overall. Compared to the handful of studies of similar arrangements $[5,9,10]$, the benefit of increased economic regulatory expertise is not being seen but the downside of conflict of interest is certainly apparent.

Despite this, the economic regulator relies on the advice of external consultants over the expertise of the regulated businesses. Economic regulatory determinations over the last ten years or so have seen the views of consultants prevail over the views of the regulated businesses and even the technical regulator. In $50 \%$ of cases, ${ }^{1}$ we found that the economic regulator approved significantly less or no safety-related capex proposed by the regulated business. This puts companies in the position of deciding whether or not to go ahead with safety-related expenditure.

In summary, the use of consultants by economic regulators has brought an imbalance between technical and economic goals as a result of the advice of consultants with insufficient expertise and/or a desire to support the economic regulator's position. This matters because, although neither the expert consultant nor the economic regulator have accountability for technical safety decisions, the economic regulator

\footnotetext{
${ }^{1} 50 \%$ of 24 economic regulatory determinations for gas supply businesses from 2010 to 2017 .
} 
unequivocally accepts the external consultants' advice and their views thereby can influence safety expenditure by gas industry duty holders.

\subsection{Conclusion}

Regulatory research has generally focused attention on the moves to risk-based regulation and forms of co-regulation. This includes some cases where regulatory functions are moved to the private sector exemplified by inspectors in the building construction sector. In this chapter, we have discussed a different category-where regulatory functions are retained by public agencies, but the actual delivery of those functions depends on the outsourcing of advice to private sector consultants.

Evidence from our research suggests that use of consultants by an economic regulator can create significant tensions with technical regulation compliance. In this case, the economic regulator's use of consultants is publicly available knowledge because the economic regulatory process produces large volumes of publicly available documentation including consultant reports. Use of consultants in other regulatory contexts is less visible, and so the impact on regulatory integrity is not as open to scrutiny.

Acknowledgements This work was funded by the Energy Pipelines Cooperative Research Centre, supported through the Australian Government's Cooperative Research Centres Program. The cash and in-kind support from the Australian Pipeline Industry Association Research and Standards Committee is gratefully acknowledged.

Ethical Statement This work was approved by the University of Sydney Human Research Ethics Committee (Project no. 2016/948). Informed consent was obtained from participants, and all data has been anonymised.

\section{References}

1. I. Ayres, J. Braithwaite, Responsive Regulation: Transcending the Deregulation Debate (Oxford University Press, New York, 1992)

2. R. Baldwin, J. Black, Really responsive regulation. The Modern Law Rev. 71(1), 59-94 (2008)

3. R. Baldwin, M. Cave, M. Lodge, Understanding Regulation: Theory, Strategy and Practice, 2nd edn. (Oxford University Press, Oxford, 2012)

4. N. Gunningham, Safety regulation and mining inspectorates-lessons from Western Australia. J. Occup. Health Safety, Australia New Zealand 21(4), 299-309 (2005)

5. J. Hackitt, Building a Safer Future Independent Review of Building Regulations and Fire Safety: Final Report (2018)

6. J. Hackitt, Building a Safer Future Independent Review of Building Regulations and Fire Safety: Interim Report (2017)

7. J. Hayes, L. Chester, D. Kramnaimuang King, ASME transactions, in Proceedings of the 12th International Pipeline Conference (IPC 2018), Calgary, Alberta, Canada, 24-28 Sept. 2018

8. A. Hopkins, Beyond compliance monitoring: new strategies for safety regulators. Law \& Policy 29(2), 210-225 (2007) 
9. J. van der Heijden, On peanuts and monkeys: private sector involvement in Australian building control. Urban Policy Res. 28(2), 195-210 (2010)

10. J. van der Heijden, Smart privatization: Lessons from private sector involvement in Australian and Canadian building regulatory enforcement regimes. J. Comp. Policy Anal. 12(5), 509-525 (2010)

Open Access This chapter is licensed under the terms of the Creative Commons Attribution 4.0 International License (http://creativecommons.org/licenses/by/4.0/), which permits use, sharing, adaptation, distribution and reproduction in any medium or format, as long as you give appropriate credit to the original author(s) and the source, provide a link to the Creative Commons license and indicate if changes were made.

The images or other third party material in this chapter are included in the chapter's Creative Commons license, unless indicated otherwise in a credit line to the material. If material is not included in the chapter's Creative Commons license and your intended use is not permitted by statutory regulation or exceeds the permitted use, you will need to obtain permission directly from the copyright holder. 